\title{
A Interface entre Arte e Matemática: em busca de perspectivas curriculares críticas e criativas
}

\author{
The Interface between Art and Mathematics: looking for critical and \\ creative curriculum perspectives
}

\begin{abstract}
Resumo
Com a finalidade de aproximar e de construir um quadro da produção científica brasileira em Educação Matemática a respeito da interface entre Arte e Matemática, este artigo apresenta os resultados de uma revisão sistemática de literatura, que analisou dissertações e teses sobre o tema em questão produzidas no período de 1998 a 2017. No âmbito curricular, discursos ligados à problemática de integração de conhecimentos e à formação cultural ampla, muitas vezes, valem-se da ideia de desenvolvimento do pensamento crítico e criativo ou criticidade e criatividade, em que se mostra na forma de objetivos, premissas ou justificativas, como se pode observar em práticas interdisciplinares, inclusive as da interface entre Arte e Matemática. Sendo assim, ocupamo-nos do seguinte problema: como as pesquisas realizadas em nível de Pós-Graduação no Brasil sobre a interface entre Arte e Matemática no contexto educacional se fundamentam no que se refere às bases teóricas assumidas em suas propostas didáticas para o ensino de Matemática? Utilizamos como perspectiva de análise questões curriculares de base crítica, em especial da Teoria Crítica e da Educação Matemática Crítica. Constatamos que todos os trabalhos que compõem essa revisão realizam a crítica do ensino de Matemática, no sentido de superação da perspectiva tradicional.
\end{abstract}

Palavras-chave: Educação Matemática. Interdisciplinaridade. Arte-Educação. Currículo de Matemática. Teoria Crítica.

\begin{abstract}
In order to approximate and build a framework of Brazilian scientific production in Mathematics Education regarding the interface between Art and Mathematics, this article presents the results of a systematic literature review, which analyzed essays and theses on this subject written from 1998 to 2017. In the curriculum scope, speeches related to the problem of knowledge integration and broad cultural formation, often use the idea of developing critical and creative thinking or criticality and creativity, in which it is shown in the form of objectives, premises, or justifications, as we can see in interdisciplinary practices, including those of the interface between

\footnotetext{
* Doutorando pelo Programa de Pós-Graduação em Educação para a Ciência, da Faculdade de Ciências da Universidade Estadual Paulista (Unesp). Técnico Administrativo em Educação no Instituto Federal de Educação, Ciência e Tecnologia de São Paulo (IFSP), Birigui, São Paulo, Brasil. Endereço para correspondência: ST-PPG Av. Eng. Luiz Edmundo Carrijo Coube, 14-01, Vargem Limpa, Bauru, São Paulo, Brasil, CEP 17033-360. E-mail: edvan.ferreira@unesp.br.

** Livre-docente em Didática e Currículo pela Universidade Estadual Paulista (Unesp). Professor associado da Faculdade de Engenharia de Ilha Solteira (FEIS) da Universidade Estadual Paulista (Unesp), Ilha Solteira, São Paulo, Brasil. Endereço para correspondência: Unesp-FEIS-DBZ, Av. Brasil n ${ }^{\circ}$ 56, Centro, Ilha Solteira, São Paulo, Brasil, CEP: 15.385-000. E-mail: harryson.lessa@unesp.br.
} 
Art and Mathematics. Therefore, we are concerned with the following problem: in regard to the theoretical bases assumed in its didactic proposals for mathematics teaching, on what are founded the researches carried out at the graduate level in Brazil at the interface between art and mathematics in the educational context? We use criticalbased curriculum issues as an analysis perspective, those ones from Critical Theory and Critical Mathematical Education. We found that all the works that make up this review criticize mathematics teaching, in the sense of overcoming the traditional perspective.

Keywords: Mathematics Education. Interdisciplinary. Art and Mathematics. Mathematics Curriculum. Critical Theory.

\section{Introdução e o caminho da pesquisa}

O que Arte tem a ver com Matemática e vice-versa? Sem querer sustentar e nem cair no famoso jargão a matemática está em tudo, identificamos conexões entre as duas áreas do conhecimento em alguns momentos. Exemplificamos dois desses momentos, considerando que, talvez, o primeiro seja mais facilmente observável; o segundo, nem tanto. São eles: (i) artistas valem-se de conhecimentos matemáticos consciente, intencional ou não, ou inconscientemente na produção de suas obras; e (ii) educadores matemáticos servem-se da Arte para produzir novos olhares e conhecimentos em Matemática e suas práticas sociais.

Sobre o primeiro momento exemplificado, em que observamos elementos constituintes da interface entre Arte e Matemática, especificamente na produção de obras de arte plásticas, vários artistas utilizaram seus conhecimentos matemáticos, a saber: Leonardo Da Vinci (14521519) - proporção áurea; Albrecht Dürer (1471-1528) - geometria projetiva; Wassily Kandinsky (1866-1944) e Piet Mondrian (1872-1944) - formas geométricas em pinturas abstratas; Maurits Cornelis Escher (1898-1972) - tesselações e pavimentações; István Orosz (1951-) - anamorfoses, etc. As relações com a Matemática no campo da visualização são identificadas de forma fácil, porém, além dessas, afere-se relações em outros domínios e manifestações da Arte, conforme apresentaremos.

No segundo momento, educadores matemáticos servem-se da Arte para produzir novos olhares e conhecimentos em Matemática e suas práticas sociais, citamos os trabalhos dos pesquisadores brasileiros em Educação Matemática que mobilizaram essa interface no intuito de constituir diferentes abordagens para a Matemática no contexto educativo. Aqui temos alguns deles e as respectivas linguagens da Arte: Abdounur (2006) - música; Poligichio (2011) - teatro; Flores (2016) - artes visuais; e Scucuglia (2012) - múltiplas linguagens. 


\title{
1.1 Construção e problematização do tema
}

No âmbito educacional, o ensino de Matemática carrega a insígnia da tendência tradicional, aquela em que o ato de ensinar se identifica como algo semelhante a uma transmissão do conhecimento e a aprendizagem como a mera recepção de conteúdos, muitas vezes, desconexos da realidade do aprendiz e sem sentido para ele. A metáfora do ensino bancário de Paulo Freire explica muito bem a relação educador-educandos nessa tendência

\begin{abstract}
A narração, de que o educador é o sujeito, conduz os educandos à memorização mecânica do conteúdo narrado. Mais ainda, a narração os transforma em 'vasilhas', em recipientes a serem 'enchidos' pelo educador. Quanto mais vá 'enchendo' os recipientes com seus 'depósitos', tanto melhor educador será. Quanto mais se deixem docilmente 'encher', tanto melhores educandos serão (FREIRE, 1987, p. 32, destaque nosso).
\end{abstract}

No mundo e no Brasil, o movimento educacional denominado Movimento da Matemática Moderna (MMM), que surgiu na década de 1960, sustentou um modelo de ensino tradicionalista que ainda ecoa na atualidade. Com forte influência política dos EUA, concorrente da corrida armamentista, o movimento preconizava a formação de cidadãos para a ciência. O objetivo era aproximar os conteúdos e a forma de ensiná-los, ao que ocorria nas universidades. A Matemática era ensinada de maneira extremamente rigorosa e descontextualizada, pautada em processos de repetição, de fórmulas e de técnicas. Tal movimento fracassou no objetivo formativo em ciência, justamente por apresentar uma didática dura e distante da realidade escolar, que, ao invés de trazer os estudantes para o conhecimento, afastava-os (PIRES, 2008).

Na busca pela superação desse movimento, começaram a surgir tendências em Educação Matemática que objetivavam uma maior integração com questões sócio-étnico-culturais a fim de tornar os processos de ensino e aprendizagem de Matemática imbuídos de significação e com vistas a uma formação mais próxima das perspectivas críticas. Dentre essas tendências, destacamos a Etnomatemática (D’AMBROSIO, 2005) e a Modelagem Matemática (BASSANEZI, 2002). Essas tendências corroboraram, por meio do trabalho acadêmico dos educadores matemáticos, para a incorporação de normativas curriculares no discurso, como aconteceu com os Parâmetros Curriculares Nacionais (PCN); dos conceitos de contextualização e interdisciplinaridade.

\footnotetext{
A perspectiva que se coloca, portanto, é a construção de currículos de Matemática mais ricos, contextualizados cultural e socialmente, com grandes possibilidades de estabelecimento de relações intra e extramatemáticas, com o rigor e a conceituação matemáticos apropriados, acessível aos estudantes, evidenciando o poder explicativo da Matemática, com estruturas mais criativas que a tradicional organização linear [...] e que deve ser uma meta a ser perseguida pelos educadores matemáticos em suas pesquisas e em suas práticas (PIRES, 2011, p. 68).
} 
A partir dos aspectos apresentados, podemos afirmar que as práticas didáticas, bem como as pesquisas sobre tais práticas (como, por exemplo, a interface entre Arte e Matemática) intensificam-se a partir desse movimento. Em decorrência das reformas curriculares, o trabalho dos educadores transforma-se para atender às propostas advindas de tais reformas. Ao investigarem o "estado da arte”, no período entre 1987 e 2013, no âmbito da Educação Matemática, Flores e Wagner (2014) afirmam que, em meados da década de 1990, começaram a surgir no Brasil estudos sobre esse tema, dos quais motivados pela instauração dos PCN e com subsídios da interdisciplinaridade, conceberam as Artes Visuais como "[...]objeto capaz de proporcionar um ensino de conceitos matemáticos ou de desenvolver habilidades visuais" (FLORES, 2016, p. 504).

No entanto, há, muitas vezes, uma má apropriação das proposições curriculares, tanto pela formação deficitária dos professores, que atuarão no processo educativo a partir dessas reformas, como pelos entraves burocráticos e de infraestrutura escolares. Dessa apropriação deficitária, emerge nosso interesse: entender como se têm fundamentado essas práticas nas pesquisas em Educação Matemática. Em quais pressupostos teóricos os educadores matemáticos têm ancorado suas propostas didáticas, para produzirem suas pesquisas no âmbito da interface entre Arte e Matemática? Como tem sido feita a apropriação dos conceitos ligados à integração curricular? É possível a incorporação de uma perspectiva de cunho crítico ao se trabalhar tal interface no contexto educacional? Visamos, ainda, a identificação de elementos das proposições didático-pedagógicas, apresentadas nesses trabalhos, os quais podem ser subsídios em potencial para o desenvolvimento do pensamento crítico e criativo por meio da interface entre Arte e Matemática.

Ao procurarmos por concepções filosóficas sobre Arte no campo da Teoria Crítica, identificamos que Theodor W. Adorno (1903-1969), Herbert Marcuse (1898-1979) e Walter Benjamin (1892-1940) sinalizam, em seus ensaios, o potencial da Arte como elemento que pode ser incorporado às questões de luta e resistência (CHAVES; RIBEIRO, 2014). De certa forma, essa ideia despertou nosso interesse na busca pelo sentido crítico de práticas educativas, como as que investigamos. No entanto, cabe destacar que nem toda Arte assume esse papel, somente a que "[...]rompe com a consciência dominante e revoluciona a experiência" (MARCUSE, 1999, p. 11). Essa Arte pode ser revolucionária em sua forma estética, quando

[...] apresenta ausência de liberdade do existente e indica forças que se rebelam contra isso; quando rompe com a realidade reificada e aponta horizontes de transformação; quando subverte as formas de percepção e compreensão e deixa transparecer um teor de verdade, de protesto e de promessa na linguagem e na imagem (CHAVES; RIBEIRO, 2014, p. 15). 
A Arte, como possibilidade de revolucionar a experiência, trata-se daquela que nos revela novas possibilidades de existir, as quais rompem com a coisificação, transformando a consciência no sentido da construção de um mundo mais justo, mais humano e pacifista.

Em vista às questões colocadas, objetivamos, neste artigo, analisar a produção científica identificada em dissertações e em teses produzidas no campo da Educação Matemática no Brasil, aquelas que têm como foco o ensino de Matemática por meio de sua interface com a Arte, a fim de buscar elementos, nas sequências ou nas proposições didáticas presentes nessas produções, instanciadores do processo formativo em Matemática orientado para a emancipação do educando. De posse dessa construção e da problematização do tema, apresentamos a seguir os procedimentos metodológicos.

\title{
1.2 Metodologia e constituição dos dados
}

Este trabalho consiste em uma revisão sistemática de literatura.

\begin{abstract}
As revisões sistemáticas são particularmente úteis para integrar as informações de um conjunto de estudos realizados separadamente sobre determinada [...] intervenção, que podem apresentar resultados conflitantes e/ou coincidentes, bem como identificar temas que necessitam de evidência, auxiliando na orientação para investigações futuras (SAMPAIO; MANCINI, 2007, p. 84, destaque nosso).
\end{abstract}

A metodologia de revisão sistemática de literatura de acordo com Sampaio e Mancini (2007) compreende cinco passos, os quais serão aplicados neste trabalho. O primeiro passo consiste na definição da pergunta de investigação.

Assim como qualquer outra investigação científica, uma boa revisão sistemática requer uma pergunta ou questão bem formulada e clara. Ela deve conter a descrição da [...] condição de interesse, a população, o contexto, a intervenção e o desfecho (SAMPAIO; MANCINI, 2007, p. 85).

Desse modo, discutimos como as pesquisas realizadas em nível de Pós-Graduação stricto sensu no Brasil sobre a interface Arte e Matemática no contexto da Educação Matemática se fundamentam no que se refere às bases teóricas assumidas em suas proposições didáticas para o ensino de Matemática?

Para a constituição dos dados de análise, levantamos produção acadêmico-científica na modalidade de dissertações e de teses, no âmbito da Pós-Graduação stricto sensu brasileira, vinculada à área de Educação Matemática e publicadas no período de 1998 até 2017. O crivo temporal justifica-se pelo fato de que nosso estudo problematiza um contexto curricular matemático brasileiro, no qual ideias relacionadas aos conceitos de contextualização e de integração vem à tona com fins de superação do ensino tradicional, que, conforme explicitado 
na problematização desta pesquisa, trata-se da consolidação da proposta dos PCN que ocorreu no Brasil em 1998.

O segundo passo envolve a busca pela evidência.

\begin{abstract}
A busca da evidência tem início com a definição de termos ou palavras-chave, seguida das estratégias de busca, definição das bases de dados e de outras fontes de informação a serem pesquisadas. [...] Uma procura eficaz envolve não só uma estratégia que inclua termos adequados, mas também a escolha de base de dados que insiram mais especificamente o tema (SAMPAIO; MANCINI, 2007, p. 85).
\end{abstract}

Para tanto, utilizamos a Biblioteca Digital de Teses e Dissertações (BDTD) ${ }^{1}$ como fonte para constituição dos dados. A BDTD é um portal de busca online que disponibiliza os textos completos das teses e das dissertações defendidas nas instituições brasileiras de ensino e de pesquisa. $\mathrm{O}$ acesso aos trabalhos por meio dessa ferramenta se dá de forma gratuita.

A revisão e a seleção dos estudos constituem o terceiro passo.

Durante a seleção dos estudos, a avaliação dos títulos e dos resumos (abstracts) identificados na busca inicial deve ser feita por pelo menos dois pesquisadores ${ }^{2},[\ldots]$ Os critérios de inclusão e exclusão são definidos com base na pergunta que norteia a revisão [...]. As discordâncias que porventura ocorram devem ser resolvidas por consenso (SAMPAIO; MANCINI, 2007, p. 86).

O procedimento de constituição dos dados para esta pesquisa deu-se em duas etapas. $\mathrm{Na}$ primeira etapa, utilizamos unitermos específicos para o levantamento, com uma posterior leitura do título e do resumo dos trabalhos. A partir da consolidação dos dados obtidos na primeira etapa, passamos, na segunda, à categorização dos trabalhos, valendo-nos de uma leitura preliminar, a fim de verificar se os trabalhos apresentam proposta didática e se ela foi desenvolvida em sala de aula e analisada pelo autor.

No penúltimo passo, analisamos a qualidade metodológica dos estudos. Sampaio e Mancini (2007) explicam que a “[...]qualidade de uma revisão sistemática depende da validade dos estudos incluídos nela. Nesta fase é importante que os pesquisadores considerem as possíveis fontes de erro (bias), que podem comprometer a relevância dos estudos em análise" (SAMPAIO; MANCINI, 2007, p. 87).

Nesse passo, devem ser aplicadas escalas de análise estatística (lista de Delphi, PEDro, OTSeeker, etc.) para quantificar a qualidade dos estudos selecionados. No entanto, consideramos a etapa desnecessária, uma vez que a revisão incorpora pesquisas realizadas em nível stricto sensu. Assim, para a análise qualitativa, dispensamos aplicação de tais escalas. A

\footnotetext{
${ }^{1}$ Disponível em http://bdtd.ibict.br/vufind/. Acesso em 04 nov. 2020.

2 A avaliação dos títulos e dos resumos foi realizada pelos autores, em consonância com as especificações metodológicas de Sampaio e Mancini (2007).
} 
Tabela 1 apresenta os termos e os algoritmos de busca utilizados, quantitativo de trabalhos identificados e de trabalhos selecionados.

Tabela 1 - Termos utilizados nas buscas e quantitativo de resultados encontrados e selecionados

\begin{tabular}{|c|c|c|c|c|}
\hline $\begin{array}{l}\text { Termo } \\
\text { utilizado }\end{array}$ & $\begin{array}{l}\text { Linguagem da } \\
\text { arte }\end{array}$ & Algoritmo de busca & $\begin{array}{l}\text { Quantitativo de } \\
\text { resultados }\end{array}$ & $\begin{array}{l}\text { Quantitativo de } \\
\text { trabalhos selecionados }\end{array}$ \\
\hline Art* & $\begin{array}{l}\text { Visual } \\
\text { Múltiplas }\end{array}$ & $\begin{array}{l}\text { Assunto: art* AND } \\
\text { matemática }\end{array}$ & 162 & 25 \\
\hline Pintura & Visual & $\begin{array}{l}\text { Assunto: pintura AND } \\
\text { matemática }\end{array}$ & 2 & 2 \\
\hline $\begin{array}{l}\text { Desenho } \\
\text { Artístico }\end{array}$ & Visual & $\begin{array}{lr}\text { Assunto: } & \text { desenho } \\
\text { artístico } & \text { AND } \\
\text { matemática } & \\
\end{array}$ & 0 & 0 \\
\hline Gravura & Visual & $\begin{array}{l}\text { Assunto: gravura AND } \\
\text { matemática }\end{array}$ & 0 & 0 \\
\hline Escultura & Visual & $\begin{array}{l}\text { Assunto: escultura AND } \\
\text { matemática }\end{array}$ & 0 & 0 \\
\hline Música & Música & $\begin{array}{l}\text { Assunto: música AND } \\
\text { matemática }\end{array}$ & 16 & 9 \\
\hline Teatro & Teatro & $\begin{array}{l}\text { Assunto: teatr* AND } \\
\text { matemática }\end{array}$ & 4 & 3 \\
\hline Dança & Dança & $\begin{array}{l}\text { Assunto: dança AND } \\
\text { matemática }\end{array}$ & 0 & 0 \\
\hline
\end{tabular}

Fonte: Adaptado de Santos (2019).

A Figura 1 apresenta os 39 trabalhos selecionados e suas relações com as linguagens da Arte desenvolvidas.

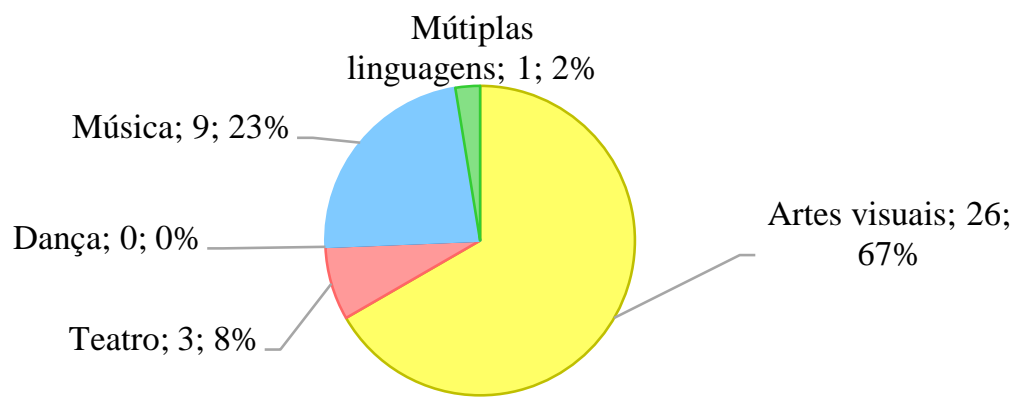

Figura 1 - Gráfico percentual de trabalhos encontrados com relação às linguagens da Arte Fonte: Adaptado de Santos (2019).

No último passo, apresentamos os resultados. Segundo Sampaio e Mancini (2007), os trabalhos "[...]incluídos na revisão sistemática podem ser apresentados em um quadro que destaca suas características principais, como: autores, ano de publicação, desenho metodológico, número de sujeitos $(\mathrm{N})$ [...] e principais resultados" (SAMPAIO; MANCINI, 2007, p. 87). A análise qualitativa dos dados constituídos iniciou por meio de uma categorização a priori, conforme especificado no Quadro 1, buscando identificar as bases teóricas que fundamentam suas propostas didáticas. Realizamos, em seguida, um processo de elaboração de sínteses dos trabalhos, analisando como foi desenvolvida a prática didática apresentada. A partir dessa análise, elaboramos um quadro de análise (cf. Quadro 4, na seção 3) que destaca características referentes às fundamentações teóricas desses trabalhos. 


\begin{tabular}{|c|c|c|c|c|c|c|}
\hline $\begin{array}{l}\text { O trabalho selecionado } \\
\text { apresenta }\end{array}$ & \multicolumn{6}{|c|}{$\begin{array}{l}\text { Proposiç̧ão didática na interface entre Arte e Matemática com foco no ensino e } \\
\text { aprendizagem de Matemática ou formação de professores }\end{array}$} \\
\hline $\begin{array}{l}\text { Que inter-relaciona a } \\
\text { Matemática com as } \\
\text { linguagens da Arte }\end{array}$ & Artes visuais & Música & Teatro & Dan & & $\begin{array}{l}\text { Múltiplas } \\
\text { linguagens }\end{array}$ \\
\hline $\begin{array}{l}\text { E que tem uma relação } \\
\text { com a fundamentação } \\
\text { teórico metodológica } \\
\text { para a proposta didática } \\
\text { caracterizada como }\end{array}$ & $\begin{array}{l}\text { Assume bas } \\
\text { crítica. }\end{array}$ & teórica & $\begin{array}{l}\text { Apresenta referen } \\
\text { crítico, mas não co } \\
\text { fundamentação } \\
\text { metodológica para } \\
\text { proposição didática. }\end{array}$ & $\begin{array}{r}\text { cial } \\
\text { a }\end{array}$ & $\begin{array}{l}\text { Assume } \\
\text { teóricas. }\end{array}$ & outras \\
\hline
\end{tabular}

Quadro 1 - Categorização a priori dos trabalhos acadêmicos selecionados Fonte: Adaptado de Santos (2019).

\section{Concepção de base teórica curricular crítica}

Constituem a base teórica curricular crítica, as tendências pedagógicas contrahegemônicas (MANFREDI, 2014), que, por sua vez, tem como um de seus princípios o materialismo histórico-dialético, a teoria marxista.

As teorias críticas são teorias de desconfiança, questionamento e transformação radical. Para as teorias críticas o importante não é desenvolver técnicas de como fazer o currículo, mas desenvolver conceitos que nos permitam compreender o que o currículo faz (SILVA, 2010, p. 30).

Essas tendências pedagógicas materializam a construção da práxis, “[...]a atividade do sujeito que de algum modo aproveita algum conhecimento ao interferir no mundo, transformando-o e se transformando a si mesmo" (KONDER, 2003, p. 2). Isto é, elas apresentaram caminhos pedagógicos, os quais traduzem uma dialética para se constituir uma abordagem pedagógica crítica.

No âmbito da Educação Matemática, identificamos a tendência Educação Matemática Crítica, proposta por Ole Skovsmose em Towards a Philosophy of Critical Mathematics Education $^{4}$ (SKOVSMOSE, 1994). Skovsmose (1994) traz uma posição crítica no que diz respeito à área, apoiando-se na Teoria Crítica da Escola de Frankfurt, projeta "as centelhas filosóficas de uma possível educação matemática crítica” (PAIS et al., 2008, p. 727). Pais e colaboradores (2008) categorizam quatro linhas de investigação, com autores que lhes são representativos, em Educação Matemática Crítica, quais sejam: (i) Estudos em Etnomatemática - Ubiratan D’Ambrósio; (ii) Estudos em subjetividade - Popkewitz, Knijnik, Walkerdine, Walls, Hardt, Cotton, entre outros; (iii) Estudos em empowerment (em português: empoderamento) - Ole Skovsmose; e, por fim, (iv) Estudos em desigualdade social - Merilyn Frankenstein, dentre outros (PAIS et al., 2008).

\footnotetext{
${ }^{3}$ Reiteramos que nenhum trabalho foi encontrado na categoria Dança.

${ }^{4}$ Livremente traduzido: Para uma Filosofia da Educação Matemática Crítica.
} 
À luz das compreensões a respeito da relação entre as bases teóricas e as práticas didáticas apresentadas, elaboramos subcategorias no decorrer das análises, as quais complementaram o entendimento da totalidade pretendida. Apresentamos, a seguir, os resultados da pesquisa.

\section{$3 \mathrm{Em}$ busca de caminhos para o desenvolvimento da criticidade e da criatividade}

Como já explicitado, esta pesquisa é uma revisão sistemática de literatura com metodologia explícita e que não deve ser confundida com pesquisas do tipo "estado da arte". Ainda que, de alguma forma, tangencia-se o que é proposto por essas pesquisas, difere-se, pois, por exemplo, não objetiva uma visão de "estado de conhecimento", ou, então, a escrita de um histórico a respeito da produção de uma determinada área, mas, sim, objetiva “[...]nortear o desenvolvimento de projetos, indicando novos rumos para futuras investigações e identificando quais métodos de pesquisa foram utilizados em uma área" (SAMPAIO; MANCINI, 2007, p. 83). Além do mais, consideramos o termo "estado da arte" controverso, pois, dentre outros motivos, ao selecionar trabalhos e categorizá-los, fazemos escolhas, desconsiderando e/ou alocando um trabalho em determinado ponto, ao passo que poderia, de distintas maneiras, estar em outro.

Nas subcategorias a posteriori indicamos como se constituiu, nesses trabalhos, a implicação da Arte para o ensino de Matemática, ou seja, como e com qual finalidade a linguagem artística se apresenta na sequência ou proposta didática.

Apresentaremos, nas categorias de linguagens da Arte, a proximidade que as fundamentações teóricas das pesquisas analisadas têm com a Teoria Crítica. Proximidade essa que é entendida no sentido da busca de verificação (i) se o trabalho fundamenta-se na teórica crítica; (ii) se apresenta referencial crítico sem que seja o embasamento teórico-metodológico para a proposta ou para a sequência didática; e (iii) se traz outras bases teóricas que não a crítica. Nesse último caso, entendemos as fundamentações no âmbito das teorias tradicionais ou das pós-críticas (SILVA, 2010), como, por exemplo, as pós-estruturalistas e as pós-modernas.

\subsection{Artes visuais}

Nesses trabalhos a relação da Arte com a Matemática se dá no âmbito da linguagem visual. Com isso, percebemos que, nesses trabalhos, a relação com a Matemática dá-se na exploração, em sua maioria, de conteúdos de geometria, os quais são identificados e 
mobilizados nas obras e expressões de artes plásticas.

Dentro da categoria de Artes Visuais, elaboramos quatro subcategorias, especificadas no Quadro 2. Em seguida, partimos para o detalhamento dessas subcategorias e as fundamentações identificadas.

i. Arte visual como meio de contextualização, manipulação e identificação de conceitos em geometria ii. Arte visual e Matemática como linguagens de expressão, percepção e compreensão da realidade

iii. Arte visual como elemento de valorização da cultura popular e/ou tradicional indígena na intersecção com o conhecimento matemático escolar

iv. Arte visual e Matemática como elementos constitutivos de diferentes e novas visualidades

Quadro 2 - Subcategorias de Artes Visuais

Fonte: Adaptado de Santos (2019).

\subsubsection{Arte visual como meio de contextualização, manipulação e identificação de conceitos em Geometria}

Nessa subcategoria, encontra-se a maior parte dos trabalhos selecionados, totalizando dezesseis: Albuquerque (2017); Antoniazzi (2005); Barros (2017); Branco (2015); Chaves (2008); Costa (2004); Ferreira (2015); Iavorski (2014); Maltez (2015); Modesto (2015); Nascimento (2017); Santos (2006); Segura (2013); Semmer (2013); Silva (2013) e Zaleski Filho (2009).

O foco da maioria desses trabalhos está no ensino-aprendizagem, com exceção do trabalho de Santos (2006), cujo foco é a formação de professores. Nessa categoria, as sequências, as oficinas ou as proposições explicitam a preocupação em desenvolver, conjuntamente com alunos ou com professores, conceitos e conteúdos matemáticos de Geometria de forma a valorizar a importância de tais conteúdos no processo formativo de Matemática.

Esse desenvolvimento dá-se em uma abordagem diferente da tradicional, daquela do ensino bancário (FREIRE, 1987). Para tanto, esses estudos buscam, nas Artes Visuais, imagens e técnicas que se dão na visualização, na manipulação, na reprodução e na identificação de conceitos geométricos, valendo-se, também, de materiais manipulativos, tais como, jogos, softwares e outros recursos. Assim, propiciam um meio, um contexto diferente do tradicional para ensinar Geometria.

Sem a pretensão de generalizar ${ }^{5}$, relatamos nossa percepção que culminou na análise e na síntese desses trabalhos. Percebemos que a maioria fundamenta suas práticas didáticas na

\footnotetext{
5 Não detalharemos as fundamentações de cada trabalho visto que cada um tem a sua construção teóricometodológica distinta, as quais entendemos não serem discrepantes do que estamos a relatar. Também o nosso
} 
interdisciplinaridade (FAZENDA, 1996; 2002; JAPIASSU, 1976) e nos PCN (contextualização) e que trazem referenciais sobre a importancia ensino de Geometria e de uso de materiais manipuláveis (LORENZATO, 2010; PAVANELLO, 1989; 1993).

No que tange à introdução da Arte no ensino de Matemática, destacamos os trabalhos de Albuquerque (2017), de Antoniazzi (2005), de Barros (2017), de Chaves (2008), de Ferreira (2015) e de Semmer (2013), por apresentarem a Proposta Triangular em Arte (BARBOSA, 2004). Nenhum trabalho nessa subcategoria apresenta fundamentação crítica como perspectiva metodológica para a prática didática; no entanto, identificamos cinco trabalhos que trazem alguns referenciais que consideramos pertencerem ao âmbito das teorias curriculares críticas (SILVA, 2010), são eles: Barros (2017), Chaves (2008), Segura (2013), Silva (2013) e Zaleski Filho (2009).

Da análise dos trabalhos dessa categoria, podemos afirmar que todos trazem elementos em suas práticas didáticas os quais podem constituir uma abordagem crítica e criativa. Tais elementos apresentam-se em forma de atividades com potencialidade explícita para superação do ensino tradicional. Percebemos que esses trabalhos trazem propostas, por meio das quais os alunos são sujeitos ativos na aula de Matemática, tendo, na aula, a oportunidade de manipularem, de criarem e de identificarem conceitos geométricos, valendo-se da Arte como um meio contextualizador. Os resultados das pesquisas mostram um envolvimento maior dos alunos nas atividades e mesmo o despertar da afetividade pela Matemática.

Não identificamos, nessas práticas, uma relação com a práxis social, no sentido de uma busca por meio dessas interrelações da Arte com a Matemática, chegando à compreensão crítica que não se restringe aos conteúdos matemáticos ou às relações desses conteúdos com a Arte, mas que chega a níveis nos quais se estabelecem relações com a realidade em que os alunos estão inseridos.

\subsubsection{Arte visual e Matemática como linguagens de expressão, percepção e compreensão da realidade}

Compõem essa subcategoria os trabalhos de Alves (2007) e de Gressler (2008), cujo foco está nos processos de ensino e de aprendizagem. Esses trabalhos apresentam uma abordagem próxima aos da subcategoria anterior, uma vez que, por meio das atividades desenvolvidas propiciam a manipulação e a identificação de conceitos matemáticos. No

objetivo não é construir uma bibliometria, mas entender como as práticas didáticas se fundamentam no âmbito dessa subcategoria. 
entanto, diferenciam-se por conceberem, de acordo com a nossa percepção, a Arte e a Matemática como linguagens e buscarem desenvolver por meio dessas linguagens a expressão, a percepção e a compreensão da realidade.

Quanto às fundamentações, Alves (2007) ancora-se na Arte-Educação, especificamente na abordagem triangular (BARBOSA, 2004) e traz Búrigo (2005) na discussão sobre o ensino de Geometria no Ensino Fundamental. Desenvolve atividades de manipulação de conceitos geométricos na construção de malhas a partir da translação de polígonos. Além de trazer o conceito de abstração (DAVIS; HERSH, 1995) e privilegiar as atividades constantes da sequência didática elaborada, processos criativos.

Gressler (2008) fundamenta-se na interdisciplinaridade (FAZENDA, 2002), nos estudos de complexidade (LEWIN, 1994) e nos os estudos de Lorenzato (1995) e Pavanello (1993) a respeito do ensino de Geometria. Com isso, a autora desenvolve um trabalho interdisciplinar na escola, envolvendo as disciplinas e professores de Matemática, Filosofia e Arte, objetivando investigar como os alunos apresentam sua compreensão complexa da realidade após o estudo de fractais numa perspectiva interdisciplinar envolvendo as disciplinas citadas.

Consideramos que os trabalhos dessa subcategoria, apesar de não incorporarem teorias críticas como perspectiva metodológica para a proposição didática, promovem uma ação em que a contextualização atinge um nível que vai além do conteúdo e, por meio das sequências didáticas, propiciam aos alunos experiências formativas que chegam ao nível da práxis, o que se percebe tanto pela ação das pesquisadoras, quanto pelos resultados apresentados nessas pesquisas.

\subsubsection{Arte Visual como elemento de valorização da cultura popular e/ou tradicional indígena na intersecção com o conhecimento matemático escolar}

Identificamos, nessa subcategoria, os trabalhos de Amador (2015) e de Madruga (2012), que se fundamentam nas tendências em Educação Matemática de Etnomatemática e Modelagem Matemática. Madruga (2012) apresenta uma pesquisa em Modelagem Matemática, ao investigar o processo cognitivo na construção de alegorias de carnaval e obtendo como resultado a constatação de que o trabalho desenvolvido na criação dessas alegorias é o mesmo que ocorre, na óptica da Modelagem, em todas as áreas do conhecimento nos trabalhos ou nas atividades cujo foco está na criação de alguma coisa.

Dessa forma, seus resultados corroboram para a valorização do conhecimento popular, validado por meio dos pressupostos da Modelagem Matemática, nas alegorias, as quais podem 
ser consideradas verdadeiras obras de arte na manifestação cultural do Carnaval. A autora cita o trabalho social realizado pelas escolas de samba, na realização de "[...]oficinas gratuitas, ministradas pelos destaques da agremiação que objetivam a formação cultural, educacional e profissional de crianças e adolescentes da comunidade[...]" (MADRUGA, 2012, p. 99). Assim, entendemos que o trabalho em Modelagem Matemática realizado pela pesquisadora tem uma perspectiva crítica ao trazer a Etnomatemática dos carnavalescos, em que a Arte das alegorias surge como um elemento de valorização da cultura popular. Valorização essa que se dá ao trazer aspectos dessa cultura por meio da sua Arte, nos quais se estabelecem intersecções com o conhecimento matemático escolar.

O trabalho de Amador (2015) é uma fantástica viagem pelo mundo cultural místico dos povos indígenas Warara-awa Assuriní. A autora constrói uma pesquisa em Etnomatemática, especificamente, em Etnomatemática em ambientes indígenas, investigando como a Arte das pinturas corporais, realizadas na aldeia Trocará, em Tucuruí (PA), pode articular-se às aulas de Matemática na aldeia, a fim de valorizar a cultura tradicional desses povos. Traz elementos significativos da cultura Assuriní, no que se refere a sua cosmologia e a sua cosmogonia, “[...]teoria sobre a origem do universo, geralmente fundada em lendas ou mitos e ligadas a uma metafísica. Em sua origem, designa toda explicação da formação do universo e dos objetos celestes. Atualmente designa as explicações de caráter mítico" (JAPIASSU; MARCONDES, 2006, p. 59).

A autora constata, ainda, que as pinturas corporais da tribo estudada têm relação intrínseca com a cultura indígena e sua inspiração decorre dos padrões identificados em animais admirados pela tribo, sendo possível, nesses padrões, identificar vários elementos geométricos. Da presença da Arte da pintura corporal na cultura indígena em uma aula de Matemática, identificamos uma possibilidade significativa de contribuição no processo formativo e na valorização da cultura tradicional indígena que advém da aproximação do conhecimento matemático formal com a cultura tradicional dessa tribo.

A partir da análise dos trabalhos dessa subcategoria, consideramos que as abordagens metodológicas da Etnomatemática e da Modelagem Matemática podem constituir perspectivas críticas e criativas no ensino de Matemática. Entendemo-las como críticas por trazerem elementos e problemáticas culturais constitutivas da realidade de grupos sociais de certa forma marginalizados em nossa sociedade. Percebemos que essas abordagens fazem sentido dentro desses grupos, em que se busca a valorização da cultura na intersecção com o conhecimento formal. No entanto, nada impede que esses elementos sejam levados para a sala de aula na disciplina de Matemática, de maneira a propiciar uma visão crítica sobre a disciplina, na forma 
como ela ganha vida nesses contextos e pode propiciar a valorização das diferentes manifestações culturais.

\title{
3.1.4 Arte visual e Matemática como elementos constitutivos de diferentes e novas visualidades
}

Dentre os trabalhos representativos dessa subcategoria (FRANCISCO, 2017; MORAES, 2014; SCHUCK, 2015; WAGNER, 2012; WAGNER, 2017), com exceção de Wagner (2017), cujo foco é a formação de professores, todos enfocam os processos de ensino e de aprendizagem. Essas pesquisas decorrem do brilhante trabalho de teorização e de orientação desenvolvido pela pesquisadora Cláudia Regina Flores que aborda visualidade e Educação Matemática (FLORES, 2016), referência evidente nessa interface.

Cabe destacar que a noção de processos de ensino e de aprendizagem, nesses trabalhos, é específica. A finalidade das oficinas identificadas em tais pesquisas não é ensinar conteúdos matemáticos, mas, sim, mobilizar e produzir diferentes e novas visualidades no "[...]cruzamento entre Arte, técnicas de olhar e Matemática" (WAGNER, 2012, p. 32). Assim, valendo-se do

[...] estudo das práticas de olhar, considerando o amplo campo de influências culturais, permite ver como atividades culturais possibilitaram a invenção de saberes técnicos, matemáticos, geométricos e, também, a elaboração e a prática de diferentes visualidades (FLORES, 2010, p. 291).

Os trabalhos que constituem essa subcategoria apresentam fundamentação no âmbito das teorias pós-estruturalistas do currículo (SILVA, 2010). Cabe destacar que o pósestruturalismo é

\begin{abstract}
[...] uma categoria bastante ambígua e indefinida, servindo para classificar um número sempre variável de autores e autoras, bem como uma série também variável de teorias e perspectivas. A lista invariavelmente inclui, é verdade, Foucault e Derrida. A partir daí, entretanto, há pouca unanimidade, cada analista fazendo a sua própria lista que pode incluir Deleuze, Guattari, Kristeva, Lacan, entre outros. É igualmente variável a genealogia que lhe é atribuída: algumas análises tomam como referência o próprio estruturalismo, principalmente Saussurre; outras preferem remeter sua gênese a Nietzche e Heiddeger. Nesse último caso, o pós-estruturalismo, além de uma reação ao estruturalismo, constitui-se numa rejeição à dialética - tanto a hegeliana quanto a marxista (SILVA, 2010, p. 117).
\end{abstract}

Dentre as fundamentações em destaque para as práticas educacionais, as quais identificamos como pós-estruturalistas, destacamos autores como Deleuze (2006), Deleuze e Guattari (1992; 2000), Foucault (1977; 1992; 2000; 2007) e Larrosa (2002; 2004; 2011).

Com esses autores, a Educação Matemática é pensada em uma perspectiva fora das relações entre ciência e técnica ou entre teoria e prática (LARROSA, 2002). Significa dizer que a Educação Matemática busca possibilidades existenciais e estéticas, no conceito de experiência 
que, diferente de experimento, não tem a necessidade de uma certeza e de uma comprovação de um método ou qualquer herança do pensamento moderno, alcançando o sujeito da experiência.

Segundo Larrosa (2002), esse sujeito é o que se permite à paixão, algo que acontece de maneira passional e não ativa. Isso não significa inatividade ou passividade. Um sujeito de paixão e de experiência é aquele que descobre, na experiência, a "[...]própria fragilidade, a própria vulnerabilidade, a própria ignorância, a própria impotência, o que vez ou outra foge ao nosso saber, ao nosso poder e à nossa vontade” (LARROSA, 2004, p. 24).

Os trabalhos dessa subcategoria apresentam uma riqueza extraordinária, no que se refere à maneira como a interface entre Arte e Matemática é desenvolvida. Riqueza essa que se expressa nas oficinas pensadas com base nos conceitos de experiência (LARROSA, 2002) e de dispositivo (DELEUZE, 1990; FOUCAULT, 2007), tendo como perspectiva metodológica para a pesquisa em Educação a cartografia (KASTRUP, 2009). São experiências que, mobilizando o conceito de visualidade em Arte e Educação Matemática, transformam o espaço escolar da Matemática, que, tradicionalmente, privilegia técnicas operatórias e o raciocínio formal. Constroem, assim, novas abordagens metodológicas que ultrapassam o simples ensino de conceitos matemáticos. Mesmo que não assumam uma perspectiva crítica do currículo, mas, sim, pós-estruturalista, além de realizarem a crítica no sentido de problematizar aspectos de formação cultural e discursiva da vista, em meio a discursos no âmbito da visualidade matemática.

\subsection{Música}

Nas pesquisas que integram essa categoria, a relação estabelecida na interface entre Arte e Matemática dá-se por meio da linguagem da música. De acordo com o PCN (BRASIL, 2006), a linguagem musical tem como estruturas morfológicas fundamentais: o som, o silêncio e seus recursos expressivos e qualidades sonoras; como estruturas sintáticas: as modalidades de organização musical, organizações sucessivas de sons, ruídos, linhas rítmicas, melódicas, tímbricas, etc. Ocorre, ainda, pelo canal de exploração de diversas fontes de criação musical, como, por exemplo, corpo e voz, sons da natureza, paisagens sonoras, sons do cotidiano, instrumentos musicais das diversas culturas, criação de novas fontes sonoras nas várias estéticas e estilos musicais (música orquestral, capoeira, samba, choro, rock, rap, etc.).

Essas pesquisas utilizam os conhecimentos inter-relacionados de Matemática e de Música por meio de analogias e modelos matemático-musicais explorados no ambiente 
educacional em atividades que envolvem a realização de experimentos matemático-musicais, a confecção de instrumentos musicais e o uso de softwares na construção de analogias e sintetizadores sonoros. Por meio da síntese e da análise desses trabalhos, entendemos que Matemática e Música são inter-relacionadas por meio de analogias e de modelos matemáticos. Apresentam como referencial teórico de destaque a teorização do pesquisador Oscar João Abdounur, cuja obra Matemática e Música: o pensamento analógico na construção de significados (ABDOUNUR, 2006) resultante de sua tese de doutorado, é uma referência significativa na interface entre Arte e Matemática, principalmente quando se trata da linguagem musical. O autor aborda a importância do pensamento analógico no ensino e na aprendizagem ao investigar como as analogias podem propiciar conexões entre afetividade e cognição.

Para Abdounur (2006), a estimulação de aptidões sensíveis, afetivas e cognitivas na proposta consonante a sua teorização, as atividades escolares desenvolvidas “[...]estariam propiciando a assimilação dos significados, a 'assemelhação' aos conceitos e um trabalho de sensibilização, fator imprescindível na construção do sentimento individual e coletivo" (ABDOUNUR, 2006, p. 326). Dentre as observações importantes colocadas por Abdounur (2006) destacamos.

Na realização das oficinas ou qualquer atividade congruente com a proposta teórica
apresentada, o professor ou coordenador da atividade deve desenvolver o hábito de
expressar, bem como extrair e 'permitir' do grupo, dentro do possível, o máximo de
significações para cada conceito abordado, o que não possui muita congruência com
as formas tradicionais de organização das atividades escolares. Tal estrutura
apresenta-se 'dissonante' com a formação dos professores em geral, bem como os
processos de avaliação tradicionais, que não respondem à flexibilidade para a
diversificação demandada pela presente proposta (ABDOUNUR, 2006, p. 316,
destaque nosso).

Compõem essa categoria os seguintes trabalhos: Almeida (2014), Barnabé (2011), Camargos (2010), Campos (2014), Depizoli (2015), Grams (2014), Misura (2016), Prado (2010) e Souza (2012), dos quais os trabalhos de Barnabé (2011), de Campos (2014), de Prado (2010) e de Souza (2012) foram orientados pelo pesquisador Oscar João Abdounur.

Quanto às fundamentações para as proposições didáticas identificamos a teorização de Abdounur (2006) acerca das relações entre Matemática e Música por meio da interdisciplinaridade a partir de Fazenda (1979; 1993; 1998) e Pombo (2008) e estudos sobre Modelagem Matemática a partir de Bassanezi (2002) e Biembengut (1990). Conforme constatamos, apenas o trabalho de Barnabé (2011) apresenta referencial crítico.

Barnabé (2011) cita Freire (1996) ao justificar que o trabalho com oficinas de Matemática e Música demandam uma perspectiva de ensino diferente da tradicinal, ou seja, 
“[...]ensinar não é transferir conhecimento, mas criar as possibilidades para a produção ou a sua construção" (FREIRE, 1996, p. 22).

Consideramos, por meio da análise desses trabalhos, que, apesar de não apresentarem referencial crítico como perspectiva metodológica para as propostas didáticas, realizam uma crítica à abordagem de ensino tradicional em Matemática. Dessa forma, contribuem para a valorização do ensino de Música nas escolas, uma vez que, mesmo havendo uma lei que normatiza o ensino de Música, devido à precarização do ensino e da formação de professores, é pouco desenvolvido no âmbito escolar. De acordo com os resultados apresentados por essas pesquisas, ao relacionar Matemática e Música, no ambiente educativo, é possível tornar a aula de Matemática mais significativa, além de propiciar afetividade pela disciplina e, também, despertar sensibilidade dos educandos pela linguagem musical.

\subsection{Teatro}

Compõem essa categoria os trabalhos que estabelecem a interface da Arte com a Matemática por meio da linguagem teatral. No PCN (BRASIL, 2006), a linguagem teatral tem como estruturas morfológicas fundamentais: movimento, voz e gesto, espaço cênico, texto, gênero e partitura cênica; como estruturas sintáticas: jogos tradicionais, jogos teatrais, improvisação, interpretação e recepção de cenas, montagem, relação entre palco e plateia, etc. Dá-se pelo canal de exploração de procedimentos de dramatização de situações, temas, transposição de textos, "[...]relacionamento com as mídias cênicas disponíveis na atualidade (cinema, vídeo, internet e outros), tendo em vista a compreensão da idéia de autoria, de encenação, das funções teatrais, dentre outras possibilidades atinentes à linguagem" (BRASIL, 2006, p. 190).

Incluem-se, nessa categoria, os trabalhos de Grützmann (2009); de Lacerda (2015) e de Poligicchio (2011). A partir da análise, como explicitado no Quadro 3, criamos subcategorias para cada trabalho, uma vez que apresentam particularidades na forma como a linguagem teatral é desenvolvida no contexto da Matemática, além de apresentarem fundamentações específicas para tais finalidades.

\begin{tabular}{|l|}
\hline i. Teatro e Matemática em jogos teatrais \\
\hline ii. Teatro e Matemática na representação de papeis \\
\hline iii. Teatro e Matemática na criação de Performances Matemáticas Digitais \\
\hline
\end{tabular}

Quadro 3 - Subcategorias de Teatro

Fonte: Adaptado de Santos (2019). 


\subsubsection{Teatro e Matemática em jogos teatrais}

O trabalho de Grützmann (2009) enfoca a formação de professores. Nesse sentido, a pesquisadora desenvolveu encontros com estudantes de Graduação, nos quais propiciou atividades que relacionassem o Teatro e a Matemática por meio de jogos teatrais. Jogos teatrais consistem em atividades cênicas cujo objetivo

[...]é a preparação e aperfeiçoamento de atores profissionais bem como ensinar teatro para iniciantes, nas escolas ou em outros grupos sociais. Cada jogo possui uma estrutura pré-estabelecida: o aluno-ator tem um foco determinado, que deve ser trabalhado a partir das instruções prévias, as quais levam o jogador a desenvolver uma parte específica da arte teatral (GRÜTZMANN, 2009, p. 33).

Quanto às fundamentações, destaca a Aprendizagem Significativa, desenvolvida por David Ausubel (MOREIRA; MASINI, 2001), Etnomatemática (D’AMBROSIO, 1996; 1997; 2001), e Jogos Teatrais (SPOLIN, 2006). Cabe destacar que a Etnomatemática não aparece como perspectiva metodológica da prática.

\subsubsection{Teatro e Matemática na representação de papéis}

Poligicchio (2011) compreende a educação como um processo que prima pelo desenvolvimento de competências pessoais necessárias para a representação de papéis durante a vida. Dessa forma, a autora defende que o caminho trilhado no desenvolvimento dessas competências perpassa a representação de papéis, que, por sua vez, esbarra tanto no Teatro, como na Matemática, uma vez que ambos estão vinculados às competências a serem desenvolvidas na Educação Básica (POLIGICCHIO, 2011). A pesquisa fundamenta-se em estudos sobre: (i) educação e desenvolvimento de competências (MACHADO, 2009); (ii) concepção de Teatro ligada à condição e necessidade humana (ORTEGA Y GASSET, 2007); (iii) obra artística como produto da representação humana (LEVEBVRE, 2006); (iv) encenação no contexto de trabalho e ação humana (ARENDT, 2010); e, também, (v) aprendizagem em experiências teatrais (DEWEY, 2010).

\subsubsection{Teatro e Matemática na criação de Performances Matemáticas Digitais}

Lacerda (2015) realiza seu trabalho com finalidade de criar Performances Matemáticas Digitais (PMDs) teatrais e analisar quais imagens da Matemática os estudantes expressam ao desenvolver PMDs teatrais. As PMDs consistem numa interlocução entre as artes performáticas, a citar música, teatro, poesia, dentre outras; e a utilização de tecnologias digitais 
em Educação Matemática (SCUCUGLIA; GADANIDIS, 2013). Scucuglia (2012) caracteriza PMD como um processo de comunicação digital de ideias matemáticas por meio de artes performáticas, da qual a produção é distribuída e divulgada por meio da internet. As PMDs são concebidas como narrativas multimodais, as quais, além da escrita, “[...]são compostas por vídeos, imagens, desenhos, simulações em flash, sons, discursos, gestos e outros elementos que compõem designs multimodais" (SCUCUGLIA, 2012, p. 18, tradução nossa do original). Uma das finalidades da PMD é a transformação da imagem negativa e estereotipada da Matemática (BORBA; SCUCUGLIA; GADANIDIS, 2013).

A pesquisa fundamenta-se em estudos sobre: o Teatro na Educação Matemática (POLIGICCHIO, 2011; RIVERA; VÉLEZ, 2014; ŞENGÜN; İSKENDEROĞLU, 2010); Performances Matemáticas Digitais (GADANIDIS; BORBA, 2008; SCUCUGLIA, 2012; SCUCUGLIA, GADANIDIS, 2013); e, Imagem Pública da Matemática (GADANIDIS; SCUCUGLIA, 2010). Traz como referencial crítico Alrø e Skovsmose (2006), cuja perspectiva teórica orienta para análise das narrativas produzidas. Por meio desse referencial, o autor discorre em alguns momentos do trabalho sobre a dialogicidade e comunicação entre professor e aluno na aula de Matemática.

\subsection{Múltiplas linguagens}

Pelo fato de o conceito de PMD integrar múltiplas linguagens da arte, o trabalho de Gregorutti (2016), que investiga como ocorre o processo de construção de imagens a respeito da Matemática por futuros professores que produzem PMD, compõe essa categoria.

A noção de PMD é problematizada em seu trabalho, ao discorrer sobre o conceito de ideologia da certeza (BORBA; SKOVSMOSE, 2001): a produção de PMD abre um espaço de experiências compartilhadas, nas quais viabilizam-se discussões, reflexões, em que é possível um afastamento de tal ideologia na medida em que se problematiza a visão de Matemática como um sistema perfeito e infalível (BORBA; SKOVSMOSE, 2001).

Consideramos que a teorização sobre PMD (GADANIDIS; BORBA, 2008; SCUCUGLIA, 2012; SCUCUGLIA; GADANIDIS, 2013) é inovadora, na medida em que integra múltiplas linguagens da Arte em uma proposta pedagógica em Matemática que objetiva comunicar ideias matemáticas em mídias digitais. Dessa forma, democratiza o conhecimento matemático em uma perspectiva criativa, além de possibilitar um olhar crítico à ideologia da certeza (BORBA; SKOVSMOSE, 2001) no processo dialógico da criação de imagens da Matemática, as quais nessa proposta são mais humanas e sensíveis. 
À guisa de conclusão desta seção, apresentamos o Quadro 4. Nele, sintetizamos as categorias das linguagens da Arte em sua interface com a Matemática por meio das subcategorias criadas, bem como suas fundamentações e a proximidade que essas fundamentações têm com a Teoria Crítica no sentido de possibilitar o agir crítico no âmbito do ensino e da prática social.

\begin{tabular}{|c|c|c|c|c|}
\hline $\begin{array}{l}\text { Linguagens } \\
\text { da arte }\end{array}$ & $\begin{array}{l}\text { Subcategorias de relação da } \\
\text { Linguagem com a Matemática }\end{array}$ & Fundamentação & $\begin{array}{l}\text { Relação da } \\
\text { fundamentação } \\
\text { com a proposição } \\
\text { didática }\end{array}$ & $\begin{array}{l}\text { Proximidade } \\
\text { com a teoria } \\
\text { crítica }\end{array}$ \\
\hline \multirow{5}{*}{ Artes visuais } & $\begin{array}{l}\text { Arte visual como meio de } \\
\text { contextualização, manipulação } \\
\text { e identificação de conceitos em } \\
\text { geometrias }\end{array}$ & & & \\
\hline & $\begin{array}{l}\text { Albuquerque (2017); Antoniazzi } \\
\text { (2005); Barros (2017); Branco } \\
\text { (2015); Chaves (2008); Costa } \\
\text { (2004); Ferreira (2015); Iavorski } \\
\text { (2014); Maltez (2015); Modesto } \\
\text { (2015); Nascimento (2017); } \\
\text { Santos (2006); Segura (2013); } \\
\text { Semmer (2013); Silva (2013) e } \\
\text { Zaleski Filho (2009). }\end{array}$ & $\begin{array}{l}\text { Teorias } \\
\text { tradicionais } \\
\text { teorias críticas }\end{array}$ & $\begin{array}{l}\text { Apresenta } \\
\text { referencial crítico, } \\
\text { mas não como } \\
\text { fundamentação } \\
\text { metodológica para a } \\
\text { proposição didática }\end{array}$ & $\begin{array}{ll}\text { Promove } & \text { a } \\
\text { crítica } & \text { no } \\
\text { âmbito } & \text { do } \\
\text { ensino } & \end{array}$ \\
\hline & $\begin{array}{l}\text { Arte visual e matemática como } \\
\text { linguagens de expressão, } \\
\text { percepção e compreensão da } \\
\text { realidade }\end{array}$ & & & \multirow{3}{*}{$\begin{array}{lr}\text { Promove } & \text { a } \\
\text { crítica } & \text { no } \\
\text { âmbito } & \text { do } \\
\text { ensino } & \mathrm{e} \\
\text { possibilita } & \mathrm{a} \\
\text { crítica } & \text { no } \\
\text { âmbito } & \text { da } \\
\text { prática social }\end{array}$} \\
\hline & $\begin{array}{l}\begin{array}{l}\text { Arte visual como elemento de } \\
\text { valorização da cultura popular } \\
\text { e/ou tradicional } \\
\text { intersecção } \\
\text { indígena na } \\
\text { conhecimento } \\
\text { escolar } \\
\text { matemático }\end{array} \\
\begin{array}{l}\text { Amador (2015) } \\
(2012) \text { e }\end{array}\end{array}$ & Teorias críticas & $\begin{array}{l}\text { Assume bases } \\
\text { teóricas críticas }\end{array}$ & \\
\hline & 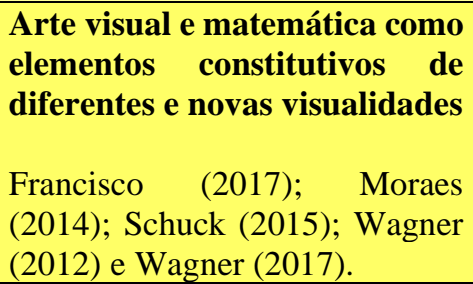 & $\begin{array}{l}\text { Teorias pós- } \\
\text { estruturalistas }\end{array}$ & $\begin{array}{l}\text { Assume } \quad \text { bases } \\
\text { teóricas pós- } \\
\text { estruturalistas }\end{array}$ & \\
\hline
\end{tabular}




\begin{tabular}{|c|c|c|c|c|}
\hline & $\begin{array}{l}\text { Música e matemática inter- } \\
\text { relacionadas por meio de } \\
\text { analogias e de modelos } \\
\text { matemáticos }\end{array}$ & \multirow{6}{*}{$\begin{array}{l}\text { Teorias } \\
\text { tradicionais } \\
\text { Teorias críticas }\end{array}$} & \multirow{6}{*}{$\begin{array}{l}\text { Apresenta } \\
\text { referencial crítico, } \\
\text { mas não como } \\
\text { fundamentação } \\
\text { metodológica para a } \\
\text { proposição didática }\end{array}$} & \multirow{3}{*}{$\begin{array}{l}\text { Promove } \\
\text { crítica } \\
\text { âmbito } \\
\text { ensino }\end{array}$} \\
\hline Música & $\begin{array}{lcr}\text { Almeida } & (2014) ; & \text { Barnabé } \\
(2011) ; & \text { Camargos } & (2010) ; \\
\text { Campos } & (2014) ; & \text { Depizoli } \\
(2015) ; \text { Grams (2014); Misura } \\
(2016) ; \text { Prado (2010) e Souza } \\
(2012) \text {. }\end{array}$ & & & \\
\hline \multirow{3}{*}{ Teatro } & $\begin{array}{l}\text { Teatro e matemática em jogos } \\
\text { teatrais } \\
\text { Grützmann (2009). }\end{array}$ & & & \\
\hline & $\begin{array}{l}\text { Teatro e matemática na } \\
\text { representação de papeis } \\
\text { Poligicchio (2011). }\end{array}$ & & & \multirow{3}{*}{$\begin{array}{lr}\text { Promove } & \text { a } \\
\text { crítica } & \text { no } \\
\text { âmbito } & \text { do } \\
\text { ensino } & \mathrm{e} \\
\text { possibilita } & \text { a } \\
\text { crítica } & \text { no } \\
\text { âmbito } & \text { da } \\
\text { prática social. }\end{array}$} \\
\hline & $\begin{array}{l}\begin{array}{l}\text { Teatro e matemática na } \\
\text { criação de Performances } \\
\text { Matemáticas Digitais }\end{array} \\
\text { Lacerda (2015). }\end{array}$ & & & \\
\hline $\begin{array}{l}\text { Múltiplas } \\
\text { linguagens }\end{array}$ & $\begin{array}{l}\text { Artes, matemática, tecnologia } \\
\text { e mídias na construção de } \\
\text { Performances Matemáticas } \\
\text { Digitais } \\
\text { Gregorutti (2016). }\end{array}$ & & & \\
\hline
\end{tabular}

Quadro 4 - Categorização dos trabalhos selecionados a respeito de suas fundamentações no âmbito curricular Fonte: Adaptado de Santos (2019)

\section{Considerações e horizontes à vista}

À guisa de conclusão, destacamos que os resultados discutidos, neste artigo, originaramse da dissertação de Santos (2019), realizada e defendida no Programa de Pós-Graduação em Educação para a Ciência, da Faculdade de Ciência (FC/Bauru), da Universidade Estadual Paulista (Unesp). Em seu trabalho, o autor discute como têm sido desenvolvidas pesquisas que lidam com a interface entre Arte e Matemática no contexto da Educação Matemática, especificamente aquelas que apresentam abordagem didática com foco no ensino e aprendizagem e formação de professores.

Ao analisarmos as perspectivas teóricas curriculares que fundamentam essas proposições percebemos, em um primeiro momento, um distanciamento da perspectiva de ensino tradicional, até mesmo nas pesquisas que não apresentam referencial de cunho crítico. Esse distanciamento é verificado nas proposições didáticas, cuja configuração tem formato diferenciado. Nessas práticas, oportunizam-se atividades de criação, por meio das quais o aluno pode desenvolver sua autonomia, expressar-se e ter uma visão diferenciada da Matemática, 
mais humana, menos estereotipada quando se estabelecem interfaces com as linguagens da Arte.

Em um segundo momento, percebemos que a maior parte das pesquisas traz referencial crítico, porém não os mobiliza no sentido de desenvolver capacidades críticas com vistas à emancipação. Isso porque eles aparecem como forma de justificativa da necessidade de uma abordagem diferenciada para a Matemática escolar no sentido de imbuir significação ao ensino e aprendizagem. Essa maioria a que nos referimos trata da subcategoria "Arte visual como meio de contextualização, manipulação e identificação de conceitos em geometria", na qual, também, identificamos uma tendência ao desenvolvimento de trabalhos na linguagem de artes visuais e, nesse aspecto, corroboramos com Flores (2016), pois o que se identifica nessas propostas “[...]é uma articulação com perspectivas mais utilitaristas, tecnicistas, ou mesmo psicologizantes do processo de ensino e aprendizagem, buscando ‘dar sentido’ à Matemática” (FLORES, 2016, p. 505). Também, devido à má-apropriação do conceito de interdisciplinaridade, parte delas resultam em abordagens que salientam "[...] dicotomias entre conhecimento e realidade que, muitas vezes, levam a um ensino que, querendo ser significativo e contextualizado, acabam sendo desprovidos de sentido, de vida" (FLORES, 2016, p. 511).

Nesse sentido, buscamos evidenciar, neste trabalho, a interface entre Arte e Matemática na Educação Matemática de uma maneira amplificada, considerando desde as buscas iniciais, as linguagens da Arte que os PCN orientam o desenvolvimento no âmbito dos conhecimentos de Arte. Observamos, também, que, dessa orientação curricular, conjecturou-se, no Brasil, um movimento culminante de desenvolvimento do tema. Apesar disso, a partir do quadro construído, constatamos que trabalhos em outras linguagens da Arte, que não a visual, são escassos ou inexistem, como é o caso da dança. É possível estabelecer interface entre dança e matemática no contexto educativo? Se sim, como? Com qual finalidade? Que perspectivas curriculares e teóricas poderiam subsidiar um trabalho de pesquisa dessa natureza?

Em nossa análise, buscamos a importância dos processos formativos em Matemática, guiados pela transformação desse mundo injusto, desigual, de crises e inúmeros problemas estruturais. Somos, paulatinamente, ceifados de nossa capacidade crítica e criativa por meio da sistematização a que estamos submetidos nas formas sociais tradicionais vigentes. Entendemos, dessa forma, que uma maneira de nos valermos de referenciais críticos na interface entre Arte e Matemática não apenas como justificativas para essas abordagens é partir de problemáticas da realidade, nas quais o aluno está inserido, e por um processo dialético consubstanciado em perspectivas curriculares críticas, a Arte, em suas múltiplas linguagens, realiza catarse: uma “expressão elaborada da nova forma de entendimento da prática social a que se ascendeu" 
(SAVIANI, 2003, p. 71-72). Ainda no que se propõe, indagamos, baseados em Skovsmose (1994), de que forma a interface entre Arte e Matemática pode ser aliada no desenvolvimento da competência democrática? O desdobramento para a questão está ligado ao potencial da Arte como elemento de luta e resistência conforme enunciamos anteriormente, no sentido de romper com a realidade reificada, apontando para horizontes de transformação.

$\mathrm{Na}$ busca por uma perspectiva crítica e criativa para o ensino de Matemática, encontramos nos trabalhos que compõem essa revisão abordagens que podem propiciar a transformação do ensino tradicional e da realidade por meio da sensibilização e do desenvolvimento da criticidade e da criatividade que se dá na contextualização, analogias, novas e diferentes visualidades e interlocução com mídias e tecnologia. Desejamos inspirar professores e pesquisadores na difusão dessas práticas educativas que mobilizam a interface Arte e Matemática, considerando também as discussões provocadas.

\section{Referências}

ABDOUNUR, O. J. Matemática e música: pensamento analógico na construção de significados. São Paulo: Escrituras, 2006.

ALBUQUERQUE, E. S. C. Geometria e arte: uma proposta metodológica para o ensino de geometria no sexto ano. 2017. 143 f. Dissertação (Mestrado Profissional em Matemática em Rede Nacional) Instituto de Matemática, Universidade Federal de Alagoas, Maceió, 2017. Disponível em: https://goo.gl/UVhzDw. Acesso em: 04 nov. 2020.

ALMEIDA, M. S. M. A Matemática de Alguns Experimentos Sonoros. 2014. 84 f. Dissertação (Mestrado Profissional em Matemática em Rede Nacional) - Instituto de Matemática, Universidade Federal da Bahia, Salvador, 2014. 84 f. Disponível em: https://goo.gl/9oM5LV. Acesso em: 02 jul. 2020.

ALRØ, H.; SKOVSMOSE, O. Diálogo e Aprendizagem em Educação Matemática. Tradução de Orlando Figueiredo. Belo Horizonte: Autêntica, 2006.

ALVES, M. L. Muito além do olhar: um enlace da matemática com a arte. 2007. 84 f. Dissertação (Mestrado em Educação em Ciências e Matemática) - Pontifícia Universidade Católica do Rio Grande do Sul, Porto Alegre, 2007. Disponível em: https://goo.gl/sFyknb. Acesso em: 04 nov. 2020.

AMADOR, A. P. A geometria das pinturas corporais e o ensino de geometria: um estudo da Escola Indígena Warara-awa Assuriní, Tucuruí, PA. 2015. 95 f. Dissertação (Mestrado em Educação Matemática e Científica) - Instituto de Educação Matemática e Científica, Universidade Federal do Pará, Belém, 2015. Disponível em: https://goo.gl/D1wQ7Q. Acesso em: 04 nov. 2020.

ANTONIAZZI, H. M. Matemática e arte: uma associação possível. 2005. Dissertação (Mestrado em Educação em Ciências e Matemática) - Pontifícia Universidade Católica do Rio Grande do Sul, Porto Alegre, 2005. Disponível em: https://goo.gl/Z9j8nw. Acesso em: 04 nov. 2020.

ARENDT, H. A condição humana. 11. ed. Rio de Janeiro: Forense Universitária, 2010.

BARBOSA, A. M. A imagem no ensino da arte. São Paulo: Perspectiva, 2004. 
BARNABÉ, F. M. A melodia das razões e proporções: a música sob o olhar interdisciplinar do professor de matemática. 2011. 68 f. Dissertação (Mestrado em Educação) - Faculdade de Educação, Universidade de São Paulo, São Paulo, 2011. Disponível em: https://goo.gl/jjV1ce. Acesso em: 04 nov. 2020.

BARROS, P. B. Z. A arte na matemática: contribuições para o ensino de geometria. 2017. Dissertação (Mestrado Profissional em Docência para a Educação Básica) - Faculdade de Ciências, Universidade Estadual Paulista "Júlio de Mesquita Filho", Bauru, 2017. Disponível em: https://goo.gl/6faJ8g. Acesso em: 04 nov. 2020.

BASSANEZI, R. C. Ensino-aprendizagem com modelagem matemática. 4. ed. São Paulo: Contexto, 2002.

BIEMBENGUT, M. S. Modelagem Matemática como Método de Ensino Aprendizagem de Matemática em cursos de 10 e 20 graus. 1990. Dissertação (Mestrado em Educação Matemática) Universidade Estadual Paulista Júlio de Mesquita Filho, UNESP, 1990.

BORBA, M. C.; SKOVSMOSE, O. A ideologia da certeza em Educação Matemática. In: SKOVSMOSE, O. Educação Matemática Crítica: a questão da democracia. Campinas: Papirus Editora, 2001. Cap. 5. p. 127-148.

BORBA, M. C.; SCUCUGLIA, R. R. S.; GADANIDIS, G. Fases das Tecnologias Digitais em Educação Matemática: sala de aula e internet em movimento. Belo Horizonte: Autêntica, 2014.

BRANCO, A. C. A má temática da dislexia: aspectos da utilização da arte e da tecnologia na aprendizagem da matemática por alunos portadores de dislexia. 2015. 242 f. Dissertação (Mestrado em Matemática) - Instituto de Matemática, Estatística e Computação Científica, Universidade Estadual de Campinas, Campinas, 2015. Disponível em: https://goo.gl/bRrvXX. Acesso em: 04 nov. 2020.

BRASIL. Secretaria de Educação Básica. Orientações curriculares para o ensino médio: Linguagens, códigos e suas tecnologias. Brasília: Secretaria de Educação Básica, 2006. Disponível em: https://goo.gl/DnpdL6. Acesso em: 04 nov. 2020.

BÚRIGO, E. Z. Para que ensinar e aprender geometria no ensino fundamental? Um exercício de reflexão sobre o currículo. In: FILIPOUSKI, A. M. R. et al. (org.). Teorias e Fazeres na escola em mudança. Porto Alegre: Editora da UFRGS, 2005. p. 243-252.

CAMARGOS, C. B. R. Música e matemática: a harmonia dos números revelada em uma estratégia de modelagem. 2010. 180 f. Dissertação (Mestrado Profissional em Educação Matemática) Universidade Federal de Ouro Preto, Ouro Preto, 2010. Disponível em: https://goo.gl/8gS5sH. Acesso em: 04 nov. 2020.

CAMPOS, G. P. S. A teoria dos conjuntos e a música de Villa-Lobos: uma abordagem didática. 2014. 94 f. Tese (Doutorado em Educação) - Faculdade de Educação, Universidade de São Paulo, São Paulo, 2014. Disponível em: https://goo.gl/BRjPUJ. Acesso em: 04 nov. 2020.

CHAVES, M. N. J. A. "Sentimento de semelhança": poéticas visuais de interconexões em arte e matemática. 2008. 129 f. Dissertação (Mestrado em Educação em Ciências e Matemática) Universidade Federal do Pará, Belém, 2008. Disponível em: https://goo.gl/MbDEdt. Acesso em: 04 nov. 2020.

CHAVES, J. C.; RIBEIRO, D. R. Arte em Herbert Marcuse: formação e resistência à sociedade unidimensional. Psicologia e Sociedade, Goiânia, v. 26, n. 1, p. 12-21, 2014. Disponível em: https://bit.ly/2YSnr3V. Acesso em: 04 nov. 2020. 
COSTA, C. O. A. A perspectiva no olhar: ciência e arte do renascimento. 2004. 198 f. Dissertação (Mestrado Profissional em Ensino de Matemática) - Pontifícia Universidade Católica de São Paulo, São Paulo, 2004. Disponível em: https://bit.ly/2MFz0UD. Acesso em: 02 jul. 2020.

D’AMBROSIO, U. Educação Matemática: da teoria à prática. Campinas: Papirus, 1996.

D’AMBROSIO, U. Transdisciplinaridade. 2. ed. São Paulo: Palas Athena. 1997.

D’AMBROSIO, U. Etnomatemática: elo entre as tradições e a modernidade. Belo Horizonte: Autêntica, 2001.

D'AMBROSIO, U. Sociedade, cultura, matemática e seu ensino. Educação e pesquisa, São Paulo, v. 31, n. 1, p. 99-120, jan./abr. 2005. Disponível em: https://goo.gl/dsgdVk. Acesso em: 04 nov. 2020.

DAVIS, Philip J.; HERSH, Reuben. A Experiência Matemática. Lisboa: Gradiva, 1995.

DELEUZE, G. Diferença e Repetição. 2. ed. São Paulo: Graal, 2006.

DELEUZE, G. O que é um dispositivo? In: DELEUZE, G. Michel Foucault, filósofo. Barcelona: Gedisa, 1990. p. 155-161.

DELEUZE, G.; GUATTARI, F. O que é Filosofia? Rio de Janeiro: Editora 34, 1992.

DELEUZE, G; GUATTARI, F. Mil Platôs: capitalismo e esquizofrenia. V. 1. Rio de Janeiro: Ed. 34, 2000.

DEPIZOLI, C. A. Matemática e música e o ensino de funções trigonométricas. 2015. $86 \mathrm{f}$. Dissertação (Mestrado em Matemática) - Universidade Tecnológica Federal do Paraná, Curitiba, 2015. Disponível em: https://goo.gl/6TyAbB. Acesso em: 04 nov. 2020.

DEWEY, John. Arte como experiência. São Paulo: Martins Fontes, 2010.

FAZENDA, I. C. A. Integração e interdisciplinaridade no ensino brasileiro. São Paulo: Loyola, 1979.

FAZENDA, I. C. A. Interdisciplinaridade: definição, projetos, pesquisa. 2. ed. [s. l.]: Cortês, 1993.

FAZENDA, I. C. A. Integração e Interdisciplinaridade no Ensino Brasileiro: efetividade ou ideologia. 4. ed. São Paulo: Loyola, 1996.

FAZENDA, I. C. A. (org.). Didática e interdisciplinaridade. Campinas: Papirus, 1998.

FAZENDA, I. C. A. (org.). Dicionário em construção: interdisciplinaridade. 2. ed. São Paulo: Cortez, 2002.

FERREIRA, R. J. Matemática e arte, um diálogo possível: trabalhando atividades interdisciplinares no $9^{\circ}$ ano do ensino fundamental. 2015. 133 f. Dissertação (Mestrado em Educação Matemática) Instituto de Ciências Exatas, Universidade Federal de Juiz de Fora, Juiz de Fora, 2015. Disponível em: https://goo.gl/tm3JiP. Acesso em: 04 nov. 2020.

FLORES, C. R. Cultura visual, visualidade, visualização matemática: balanço provisório, propostas cautelares. Zetetiké, Campinas, v. 18, p. 271-294, 2010. Disponível em: https://bit.ly/2NRIxJz.

Acesso em: 04 nov 2020. 
FLORES, C. R. Descaminhos: potencialidades da arte com a educação matemática: potencialidades da Arte com a Educação Matemática. Bolema, Rio Claro, v. 30, n. 55, p. 502-514, ago. 2016. Disponível em: https://bit.ly/2NMyiWZ. Acesso em: 04 nov. 2020.

FLORES, C. R.; WAGNER, D. R. Um mapa e um inventário da pesquisa brasileira sobre arte e educação matemática. Educação Matemática Pesquisa, São Paulo, v. 16, n. 1, p. 243-258, jan. 2014. Disponível em: https://bit.ly/31EJ09R. Acesso em: 04 nov. 2020.

FOUCAULT, M. Vigiar e Punir. Petrópolis: Vozes, 1977.

FOUCAULT, M. As palavras e as coisas. 6. ed. São Paulo: Martins Fontes, 1992.

FOUCAUlT, M. A Arqueologia do Saber. 6. ed. Rio de Janeiro: Forense Universitária, 2000.

FOUCAUlT, M. Microfísica do Poder. 24. ed. Rio de Janeiro: Edições Graal, 2007.

FRANCISCO, B. M. Um oficinar-de-experiências que pensa com crianças: matemáticas-cubistas, formas brincantes e ex-posições. 2017. 266 f. Dissertação (Mestrado em Educação Científica e Tecnológica) - Centro de Ciências da Educação, Universidade Federal de Santa Catarina, Florianópolis, 2017. Disponível em: https://goo.gl/nfNQnW. Acesso em: 04 nov. 2020.

FREIRE, P. Pedagogia do oprimido. 17. ed. Rio de Janeiro: Paz e Terra, 1987.

FREIRE, P. Pedagogia da autonomia: saberes necessários à prática educativa. São Paulo: Paz e Terra, 1996.

GADANIDIS, G.; BORBA, M. C. Our lives as performance mathematicians. For the Learning of Mathematics, Edmonton, v. 28, n. 1, p. 44-51, 2008. Disponível em: https://bit.ly/3mUaNuE. Acesso em: 04 nov. 2020.

GADANIDIS, G.; SCUCUGLIA, R. R. S. Windows into Elementary Mathematics: Alternate public images of mathematics and mathematicians. Acta Scientiae, Canoas, v. 12, p. 8-23, 2010. Disponível em: https://bit.ly/313YlYA. Acesso em: 04 nov. 2020.

GRAMS, A. L. B. Modelagem matemática no ensino médio: percepção matemática por meio da música. 2014. 191 f. Dissertação (Mestrado em Educação em Ciências e Matemática) - Pontifícia Universidade Católica do Rio Grande do Sul, Porto Alegre, 2014. Disponível em: https://goo.gl/TVTKXR. Acesso em: 04 nov. 2020.

GREGORUTTI, G. S. Performance matemática digital e imagem pública da matemática: viagem poética na formação inicial de professores. 2016. 63 f. Dissertação (Mestrado em Educação Matemática) - Instituto de Geociências e Ciências Exatas, Universidade Estadual Paulista "Júlio de Mesquita Filho", Rio Claro, 2016. Disponível em: https://goo.gl/zuBg1N. Acesso em: 04 nov. 2020.

GRESSLER, M. D. Construindo uma Percepção Complexa da Realidade a partir do Estudo dos Fractais. 2008. 150 f. Dissertação (Mestrado em Educação em Ciências e Matemática) - Pontifícia Universidade Católica do Rio Grande do Sul, Porto Alegre, 2008. Disponível em: https://goo.gl/SB1uRt. Acesso em: 04 nov. 2020.

GRÜTZMANN, T. P. A formação dos professores de matemática por meio dos jogos teatrais. 2009. 133 f. Dissertação (Mestrado em Educação em Ciência e Matemática) - Faculdade de Física, Pontifícia Universidade Católica do Rio Grande do Sul, Porto Alegre, 2009. Disponível em: https://bit.ly/3oNwhLg. Acesso em: 04 nov. 2020. 
IAVORSKI, C. Anamorfose: uma arte no ensino de matemática e sua aplicação em atividades interdisciplinares. 2014. 79 f. Dissertação (Mestrado Profissional em Matemática em Rede Nacional) Universidade Tecnológica Federal do Paraná, Curitiba, 2014. Disponível em: https://goo.gl/waWj1B. Acesso em: 04 nov. 2020.

JAPIASSU, H. Interdisciplinaridade e patologia do saber. Rio de Janeiro: Imago, 1976.

JAPIASSU, H.; MARCONDES, D. Dicionário básico de filosofia. 4. ed. Rio de Janeiro: Zahar, 2006.

KASTRUP, V. O funcionamento da atenção no trabalho do cartógrafo. In: PASSOS, E.; KASTRUP, V.; ESCÓSSIA, L. (org.). Pistas do método da cartografia: pesquisa- intervenção e produção de subjetividade. Porto Alegre: Sulina, 2009. p. 32-51.

KONDER, L. A dialética e o marxismo. Trabalho Necessário, Niterói, v. 1, n. 1, p.1-10, 2003. Disponível em: https://bit.ly/2GdSq2r. Acesso em: 04 jul. 2020.

LACERDA, H. D. G. Educação matemática encena. 2015. 179 f. Dissertação (Mestrado em Educação Matemática) - Instituto de Geociências e Ciências Exatas, Universidade Estadual Paulista, Rio Claro, 2015. Disponível em: https://goo.gl/6nkePc. Acesso em: 04 nov. 2020.

LARROSA, J. Notas sobre a experiência e o saber de experiência. Revista brasileira de educação, Rio de Janeiro, v. 19, n. 1, p. 20-29, jan./fev./mar./abr. 2002. Disponível em: https://bit.ly/3eVacoT. Acesso em: 04 nov. 2020.

LARROSA, J. Algunas notas sobre la experincia y suas lenguajes. In: BARBOSA, R. L. L. B. (org). Trajetórias e perspectivas da formação de educadores. São Paulo: Ed UNESP, 2004. p. 19-34.

LARROSA, J. Experiência e alteridade em educação. Reflexão e Ação, Santa Cruz do Sul, v. 19, n. 2, p. 4-27, 2011. Disponível em: https://bit.ly/31HeT1F. Acesso em: 04 nov. 2020.

LEFEBVRE, H. La presencia y la ausência: contribuición a la teoria de las representaciones. Tradução de Óscar Barahona y Uxoa Doyhamboure. México: FCE, 2006.

LEWIN, R. Complexidade: a vida no limite do caos. Rio de Janeiro: Rocco, 1994.

LORENZATO, S. Por que não ensinar geometria? Educação Matemática em Revista, Blumenau, v. 3, n. 4, p. 3-13, 1995.

LORENZATO, S. A. (org.). Laboratório de ensino de matemática e na formação de professores. 3. ed. Campinas: Autores Associados, 2010.

MACHADO, N. J. Educação: microensaios em mil toques. São Paulo: Escrituras, 2009.

MADRUGA, Z. E. F. A criação de alegorias de carnaval: das relações entre modelagem matemática, etnomatemática e cognição. 2012. 133 f. Dissertação (Mestrado em Educação em Ciências e Matemática) - Pontifícia Universidade Católica do Rio Grande do Sul, Porto Alegre, 2012. Disponível em: https://goo.gl/MUzZBb. Acesso em: 04 nov. 2020.

MALTEZ, L. S. C. Geometria projetiva: Matemática e Arte. 2015. 56 f. Dissertação (Mestrado Profissional em Matemática em Rede Nacional) - Instituto de Matemática, Universidade Federal da Bahia, Salvador, 2015. Disponível em: https://goo.gl/PdXJPn. Acesso em: 04 nov. 2020.

MANFREDI, M. N. G. P. Educação e contra hegemonia na década neoliberal: as tendências pedagógicas contra-hegemônicas entre a crise paradigmática e a construção de outra hegemonia possível no limiar do século XXI. 2014. Tese (Doutorado em Educação) - Pontifícia Universidade 
Católica de São Paulo, São Paulo, 2014. Disponível em: https://bit.ly/2BbRck5. Acesso em: 04 jul. 2020.

MARCUSE, H. A dimensão estética. Lisboa: Edições 70, 1999.

MISURA, C. Um olhar sobre os modelos matemáticos da música. 2016. 88 f. Dissertação (Mestrado Profissional em Matemática em Rede Nacional) - Universidade Federal do ABC, Santo André, 2016. Disponível em: https://bit.ly/2I3qMVI. Acesso em: 04 jul. 2020.

MODESTO, C. F. Matemática e arte: explorando a geometria dos fractais e as tesselações de Escher. 2015. 146 f. Dissertação (Mestrado Profissional em Matemática em Rede Nacional) - Centro de Ciências Exatas, Universidade Estadual de Londrina, Londrina, 2015. Disponível em: https://goo.gl/rSE1Va. Acesso em: 04 nov. 2020.

MORAES, J. C. P. Experiências de um corpo em Kandinsky: formas e deformações num passeio com crianças. 2014. 220 f. Dissertação (Mestrado em Educação Científica e Tecnológica) - Centro de Ciências da Educação, Universidade Federal de Santa Catarina, Florianópolis, 2014. Disponível em: https://goo.gl/EsZ7if. Acesso em: 04 nov. 2020.

MOREIRA, M. A.; MASINI, E. F. S. Aprendizagem significativa: a teoria de David Ausubel. São Paulo: Centauro, 2001.

NASCIMENTO, A. T. Aproximações entre artes visuais e matemática: possibilidades de produção do livro ilustrado a partir das formas geométricas. 2017. 163 f. Dissertação (Mestrado em Ensino de Ciência e Tecnologia) - Universidade Tecnológica Federal do Paraná, Ponta Grossa, 2017. Disponível em: https://goo.gl/4oebZL. Acesso em: 04 nov. 2020.

ORTEGA Y GASSET, J. A ideia do Teatro. São Paulo: Perspectiva, 2007.

PAIS, A. et al. O conceito de crítica em educação matemática e perspectivas de investigação. In: INVESTIGACIÓN EN EDUCACIÓN MATEMÁTICA, 12., 2008, Badajoz. Anais... Badajoz: Sociedad Española de Investigación en Educación Matemática - SEIEM, 2008. p. 725 - 734. Disponível em: https://bit.ly/37yjYub. Acesso em: 05 nov. 2020.

PAVANELLO, M. R. O abandono do ensino de geometria: uma visão histórica. 1989. 196 f. Dissertação (Mestrado em Educação) - Universidade Estadual de Campinas, Campinas, 1989. Disponível em: https://bit.ly/2Sf9qeQ. Acesso em: 04 nov. 2020.

PAVANELLO, M. R. O abandono do ensino da geometria no Brasil: causas e consequiências.

Zetetiké, Campinas, v. 1, n. 1, p. 7-17, 1993. Disponível em: https://bit.ly/2YSMkfW. Acesso em: 04 nov. 2020.

PIRES, C. M. C. Educação Matemática e sua influência no processo de organização e desenvolvimento curricular no Brasil. Bolema, Rio Claro, v. 21, n. 29, p. 13-42, 2008. Disponível em: https://bit.ly/34V7vB4. Acesso em: 04 nov. 2020.

PIRES, C. M. C.; SILVA, M. A. Desenvolvimento curricular em Matemática no Brasil: trajetórias e desafios. Quadrante, Lisboa, v. 20, n. 2, p. 57-80, jun. 2011. Disponível em: https://bit.ly/2VGgsZT. Acesso em: 04 nov. 2020.

POLIGICCHIO, A. G. Teatro: materialização da narrativa matemática. 2011.148 f. Dissertação (Mestrado em Educação, Faculdade de Educação) - Universidade de São Paulo, São Paulo, 2011. Disponível em: https://goo.gl/i89a8Z. Acesso em: 04 nov. 2020. 
POMBO, O. Epistemologia da interdisciplinaridade. Ideação, Foz do Iguaçu, v. 10, n. 1, p. 9-40, 2008. Disponível em: https://bit.ly/2I15DxE. Acesso em: 04 nov. 2020.

PRADO, L. A. G. Matemática, física e música no Renascimento: uma abordagem históricoepistemológica para um ensino interdisciplinar. 2010. 110 f. Dissertação (Mestrado em Educação) Faculdade de Educação, Universidade de São Paulo, São Paulo, 2010. Disponível em: https://goo.gl/f9NUFT. Acesso em: 04 nov. 2020.

RIVERA, E. R.; VÉLEZ, W. C. El uso del teatro como herramienta didáctica en la enseñanza de la estadística. Cuaderno de Investigación en la Educacion, Puerto Rico, v. 29, p. 47-58, 2014. Disponível em: https://bit.ly/32fzj19. Acesso em: 04 nov. 2020.

SAMPAIO R. F.; MANCINI, M. C. Estudos de revisão sistemática: um guia para síntese criteriosa da evidência científica. Revista Brasileira de Fisioterapia, São Carlos, v. 11, n. 1, p.83-89, fev. 2007. Disponível em: https://bit.ly/2GcihE4. Acesso em: 04 nov. 2020.

SANTOS, E. F. A interface Arte e Matemática: em busca de uma perspectiva crítica e criativa para o ensino de matemática. 2019. 174 f. Dissertação (Mestrado em Educação para a Ciência) - Faculdade de Ciências, Universidade Estadual Paulista "Júlio de Mesquita Filho", Bauru, 2019. Disponível em: https://bit.ly/2HbDQGM. Acesso em 04 nov. 2020.

SANTOS, M. R. Pavimentações do plano: um estudo com professores de matemática e arte. 2006. 177 f. Dissertação (Mestrado em Educação Matemática) - Instituto de Geociências e Ciências Exatas, Universidade Estadual Paulista, Rio Claro, 2006. Disponível em: https://goo.gl/kCjT8v. Acesso em: 04 nov. 2020.

SAVIANI, D. Escola e democracia. 36. ed. Campinas: Autores associados, 2003.

SCHUCK, C. A. Cartografar na diferença: entre imagens, olhares ao infinito e pensamento matemático. 2015. 210 f. Dissertação (Mestrado em Educação Científica e Tecnológica) - Centro de Ciências da Educação, Universidade Federal de Santa Catarina, Florianópolis, 2015. Disponível em: https://goo.gl/s6wXpu. Acesso em: 04 nov. 2020.

SCUCUGLIA, R. R. s. On the Nature of Students' Digital Mathematical Performances. 2012. 264 f. Tese (Doutorado em Educação) - Universidade de Western Ontario, Londres, 2012. Disponível em: https://bit.ly/3oSth0l. Acesso em: 04 nov. 2020.

SCUCUGLIA, R. R. S.; GADANIDIS, G. Performance Matemática: Tecnologias Digitais e Artes da Escola Pública de Ensino Fundamental. In: BORBA, M. C.; CHIARI, A. S. S. (org.).

Tecnologias Digitais e Educação Matemática. São Paulo: Livraria da Física, 2013. p. 325-363.

SEGURA, C. S. C. Releitura de obras de arte pelo viés da geometria analítica: uma proposta para o ensino interdisciplinar da matemática. 2013. 110 f. Dissertação (Mestrado Profissional em Matemática em Rede Nacional) - Centro de Ciências Exatas, Universidade Estadual de Londrina, Londrina, 2013. Disponível em: https://goo.gl/anxqzT. Acesso em: 04 nov. 2020.

SEMMER, S. Ensino de geometrias não-euclidianas usando arte e matemática. 2013. 268 f. Dissertação (Mestrado em Ensino de Ciência e Tecnologia) - Universidade Tecnológica Federal do Paraná, Ponta Grossa, 2013. Disponível em: https://goo.gl/F5cuAY. Acesso em: 04 nov. 2020.

ŞENGÜN, Y.; İSKENDEROĞLU, T. A review of creative drama studies in math education: aim, data collection, data analyses, sample and conclusions of studies. Procedia Social and Behavioral Sciences, Trabzon, v. 9, p. 1214-1219, 2010. Disponível em: https://bit.ly/2ZuuNK5. Acesso em: 04 nov. 2020. 
SILVA, A. P. Matemática na arte: análise de uma proposta de ensino envolvendo a pintura renascentista e a Geometria em uma classe do $9^{\circ}$ ano do Ensino Fundamental em Belo Horizonte (MG). 2013. 201 f. Dissertação (Mestrado em Educação Matemática) - Instituto de Ciências Exatas e Biológicas, Universidade Federal de Ouro Preto, Ouro Preto, 2013. Disponível em: https://bit.ly/2Bwabcr. Acesso em: 04 nov. 2020.

SILVA, T. T. Documento de identidade. 3. ed. Brasil: Autêntica, 2010.

SKOVSMOSE, O. Towards a Philosophy of Critical Mathematics Education. Dordrecht: Kluwer Academic Publishers, 1994.

SOUZA, L. G. S. Uma abordagem didático-pedagógica da racionalidade matemática na criação musical. 2012. 298 f. Tese (Doutorado em Educação) - Faculdade de Educação, Universidade de São Paulo, São Paulo, 2012. Disponível em: https://goo.gl/cZCEpb. Acesso em: 04 nov. 2020.

SPOLIN, V. Jogos teatrais: o fichário de Viola Spolin. 2. ed. São Paulo: Perspectiva, 2006.

WAGNER, D. R. Arte, técnica do olhar e Educação Matemática: o caso da perspectiva central na pintura clássica. 2012. 124 f. Dissertação (Mestrado em Educação Científica e Tecnológica) Universidade Federal de Santa Catarina, Florianópolis, 2012. Disponível em: https://goo.gl/68KL5w. Acesso em: 04 nov. 2020.

WAGNER, D. R. Visualidades movimentadas em oficinas-dispositivo pedagógico: um encontro entre imagens da arte e professores que ensinam matemática. 2017. Tese (Doutorado em Educação Científica e Tecnológica) - Centro de Ciências da Educação, Universidade Federal de Santa Catarina, Florianópolis, 2017. Disponível em: https://goo.gl/kYxRRn. Acesso: em 04 nov. 2020.

ZALESKI FILHO, D. Arte e matemática em Mondrian. 2009. 168 f. Dissertação (Mestrado em Educação, Arte, e História da Cultura) - Universidade Presbiteriana Mackenzie, São Paulo, 2009. Disponível em: https://goo.gl/dMtfu1. Acesso em: 04 nov. 2020. 